This journal is the official publication of Bangladesh Society of Physiologists (BSP)

Web URL: www.banglajol.info/index.php/JBSP

Abstracted /indexed in Index Copernicus, Director of Open Access Journal, Index Medicus for South East Asia Region, Google Scholar, 12OR, infobse index, Open J gate, Cite factor, Scientific indexing services

pISSN-1983-1213; e-ISSN-2219-7508

\title{
Article
}

Article information:
Received on March 2019
Accepted on June 2019
DOI: https://oi.org/10.3329/jbsp.v14i1.42000

Corresponding author:

Fatema Tuz Munira, Department of Physiology, Armed Forces Medical College, Dhaka,

E-mail: munira277@yahoo.com

Cite this article:

Munira FT, Begum S. Serum zinc,copper, ferritin levels in transfusion dependent thalassemia patients with iron chelator therapy

J Bangladesh Soc Physiol 2019;14(1): 38-42

This article is open access licensed under CC BY NC SA which allows readers copy, distribute, display, and perform the work and make derivative works based on it only for noncommercial purposes.

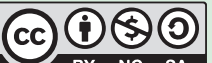

\section{Serum zinc, copper and ferritin levels in transfusion dependent thalassemia patients with iron chelator therapy}

Fatema Tuz Munira ${ }^{1}$, Shelina Begum ${ }^{2}$

1. Department of Physiology, Armed Forces Medical College, Dhaka

2. Department of Physiology, Bangabandhu Sheikh Mujib Medical University, Dhaka

Abstract

Background: Transfusion dependent thalassemia (TDT) patients require regular blood transfusion and iron chelator therapy to maintain their life. Iron chelator may alter serum zinc and copper level in TDT patients. Objective: To observe serum zinc and copper and ferritin levels in transfusion dependent thalassemic patients treated with iron chelator. Method: The present cross sectional study was carried out in the department of Physiology, BSMMU, Dhaka between September 2017 to February 2019. Thirty cases of TDT, aged 5-40 year were included in the study group. Age and sex matched 30 healthy subjects were also studied as control. All the TDT patients were selected from the outpatient Department of Hematology and Transfusion Medicine, BSMMU, Dhaka. Serum zinc was measured by Spectrophotometric method and serum copper and ferritin levels were measured by colorimetric method. For statistical analysis independent sample $t$ test was used. Result: The mean serum zinc level was significantly $(\mathrm{p}<0.05)$ lower and serum ferritin level was significantly $(\mathrm{p}<0.001)$ higher in TDT compared to control. Again, mean serum copper level and $\mathrm{Zn} / \mathrm{Cu}$ ratio were not significantly ( $\mathrm{p}>0.05)$ different in study groups compared to that of control. In addition, $3.3 \%$ TDT patients had hypozincemia and $13.3 \%$ TDT patients had hypercupremia. Conclusion: This study may conclude that low serum zinc level and high copper level may be associated with TDT patients treated by combined deferoxamine (DFO) \& deferiprone (DFP) iron chelator.

Key words: TDT, zinc, copper and iron chelators (DFP and DFO) 
Introduction

7 halassemia is a group of autosomal recessive hereditary blood disorder in which there are defective synthesis of alpha or beta globin subunit of hemoglobin. ${ }^{1-2}$ About 150 million people carry the thalassemia gene worldwide ${ }^{2-3}$ but it is most common in Mediterranean regions, Middle East, part of Africa, Central Asia, India sub-continent, Southern China and into the Pacific island ${ }^{3-4}$. According to World Health Organization, about $3 \%$ of population is carrier of beta thalassemia and about $4 \%$ population is carrier of $\mathrm{Hb}-\mathrm{E}$ in Bangladesh $^{5-6}$.

The principal treatment of thalassemia involve blood transfusion to correct anemia ${ }^{1}$. The repeated blood transfusion may lead to accumulation of excess iron in the body ${ }^{3}$ causing oxidative stress and organ damage ${ }^{4-5}$. The most common cause of death is heart failure due to transfusional iron overload ${ }^{1}$. So, several iron chelators have also been used to remove the excess iron from the body ${ }^{3}$. Currently there are three approved commercially available iron chelators - deferoxamine (DFO), deferiprone (DFP), deferasirox (DFX) ${ }^{7}$.

Ferritin binds with iron and stores excess iron within the cell and iron overload causes high concentration of serum ferritin. Therefore, estimation of serum ferritin is most commonly used to evaluate iron overload in patients with thalassemia $^{8-10}$.

Among minerals, zinc is essential in many biological processes. Zinc act as a cofactor for more than 300 enzymes and it is actively involved in DNA synthesis, cellular growth, wound healing, protein synthesis, fertility, conception, immune system and metabolism. It has antioxidant properties also 4,8,11-12. Zinc deficiency causes growth retardation, hypogonadism, infection, impaired wound healing, decreased bone mineral density, impaired glucose tolerance, neurological disturbance etc. ${ }^{1,11}$.
In our body, copper is widely distributed in tissues in the form metalloproteins acting on enzymes ${ }^{12}$.Copper is the major component of hemoglobin and required for production of hormone. It has also antioxidant properties ${ }^{11}$. It acts as a co-factor of enzymatic reaction including cytochrome c oxidase, lysyl oxidase, superoxide dismutase, catalases, thyroginase and glutathione peroxidase ${ }^{4}$. Excess copper is responsible for vomiting, hypotension, maelena, gastrointestinal disturbance and wilson's disease 1,11. Data on these minerals in TDT patients treated with iron chelator is very scarce. Therefore, this study has been designed to evaluate zinc and copper and ferritin levels in TDT patients treated with iron chelator.

\section{Methods}

The present cross sectional study was carried out in the department of Physiology, BSMMU, Dhaka between September 2017 to February 2019 and protocol of this study was approved by Institutional Review Board, BSMMU. Serum zinc, copper, ferritin and $\mathrm{Hb}$ levels of $30 \mathrm{TDT}$ patients treated with combined iron chelator (DFP) and (DFO) and 30 healthy subjects (control), age ranged from 5-40 years were assessed. TDT patients were selected from outpatient Department of Hematology and Transfusion Medicine, BSMMU and control were selected among the relatives and attendants of patients, hospital staff and subjects available in the BSMMU campus and also by personal contact. Subjects with history of renal disease, any acute and chronic disease, vitamins and minerals supplementation were excluded from the study. After selection of the subjects, the purpose of the study was explained to each subjects and informed written consent was taken. Detailed family and medical history, anthropometric measurement were recorded. For estimation of serum copper, zinc, ferritin and $\mathrm{Hb}$ levels $5 \mathrm{ml}$ of venous blood was collected from ante-cubital vein under aseptic precaution from each subjects and serum was prepared for these biochemical 
tests. Serum zinc was measured by Spectrophotometric method and serum copper and ferritin was measured by colorimetric method. Data were expressed as Mean \pm SE. Data analysis was done with SPSS version 16. For statistical analysis independent sample t test and Chi-Square test were performed.

\section{Results}

In this study, all the groups were matched for age and sex but BMI $(\mathrm{p}<0.05)$ and $\mathrm{Hb}(\mathrm{p}<0.001)$ were significantly lower in TDT compared to that of control (Table I). Mean serum zinc level was significantly $(\mathrm{p}<0.05)$ lower and mean serum ferritin was significantly $(\mathrm{p}<0.001)$ higher in TDT patients compared to that of control. There was no significant difference in mean serum copper and $\mathrm{Zn} / \mathrm{Cu}$ ratio between TDT and control subjects (Table II).

Again, in this study $3.3 \%$ TDT patients had hypozincemia and $13.3 \%$ TDT patients had hypercupremia. No control had hypozincemia or hypercupremia (Table III).

TableI: Age, $\mathrm{BMI}$ and $\mathrm{Hb}$ in both groups $(\mathrm{N}=60)$

\begin{tabular}{lcc}
\hline Parameter & Control $(\mathrm{n}=30)$ & TDT $(\mathrm{n}=30)$ \\
\hline Age $($ years $)$ Mean \pm SE & $19.86 \pm 1.57$ & $19.66 \pm 1.68$ \\
Male no $(\%)$ Female no( $\%)$ & $15(50 \%) 15(50 \%)$ & $15(50 \%) 15(50 \%)$ \\
$\mathrm{BMI}\left(\mathrm{Kg} / \mathrm{m}^{2}\right)$ Mean \pm SE & $21.87 \pm 0.89$ & $18.54 \pm 0.56^{*}$ \\
$\mathrm{Hb}(\mathrm{g} / \mathrm{dl})$ Mean \pm SE & $13.75 \pm 0.19$ & $7.78 \pm 0.36^{* * *}$ \\
\hline
\end{tabular}

Statistical analysis was done by independent sample $t$ test and Chi-Square test.BMI-Body mass index;Hb-Hemoglobin; TDT-Transfusion dependent thalassemia; ${ }^{*} \mathrm{p}<0.05,{ }^{* *} \mathrm{p}<0.001$.

Table II: Serum zinc, copper, $\mathrm{zn} / \mathrm{cu}$ ratio and ferritin levels in both groups $(\mathrm{N}=60)$

\begin{tabular}{lcc}
\hline Parameter & Control $(\mathrm{n}=30)$ & TDT $(\mathrm{n}=30)$ \\
\hline Serum zinc $(\mathrm{mg} / \mathrm{L})$ & $0.78 \pm 0.01$ & $0.70 \pm 0.01^{*}$ \\
Serum copper $(\mu \mathrm{g} / \mathrm{dl})$ & $98.90 \pm 5.23$ & $100.70 \pm 5.98$ \\
Zn/Cu ratio & $0.009 \pm 0.001$ & $0.008 \pm 0.001$ \\
Serum ferritin $(\mu \mathrm{g} / \mathrm{L})$ & $40.39 \pm 7.68$ & $6276.85 \pm 709.82^{* * *}$ \\
\hline
\end{tabular}

Data are expressed as Mean \pm SE. Statistical analysis was done by independent sample t test.TDTTransfusion dependent thalassemia; $* \mathrm{p}<0.05, * * * \mathrm{p}<0.001$.

Table III: Frequency of subjects by hypozincemia, hypercupremia in both groups $(\mathrm{N}=60)$

\begin{tabular}{lcc}
\hline Parameters & Control $(\mathrm{n}=30)$ & TDT $(\mathrm{n}=30)$ \\
\hline & no. $(\%)$ & no. $(\%)$ \\
Hypozincemia & $00(0)$ & $1(3.3)$ \\
Hypercupremia & $00(0)$ & $4(13.3)$ \\
\hline
\end{tabular}

Data are expressed as no. \%. TDT-Transfusion dependent thalassemia. Cut point for zinc-.55mg/L cut point for copper- $155 \mathrm{microgram} / \mathrm{dl}$ 


\section{Discussion}

The present study observed serum zinc and copper and ferritin levels of TDT patients treated with combined iron chelators.

The result of this study showed significantly lower serum zinc level in all TDT patients than control. Similar observation were published by others ${ }^{13-14}$. On the other hand, normal serum zinc level was observed in TDT patient treated with DFP and DFO iron chelator separately ${ }^{8,15}$. In the present study, serum copper level of TDT was not significantly different than control. But Mashhadi found lower level of serum copper in TDT patients treated with combined iron chelator and Genc et al. also found similar result in patients treated with DFP iron chelator ${ }^{8,16}$. Moreover, significant number of TDT in this study were suffering from zinc deficiency and excess copper.

The presence of $\mathrm{Zn}$ deficiency, $\mathrm{Cu}$ excess in the TDT patients under combined chelator therapy cannot be explained from this study. The body of literature suggested that decreased serum zinc level may be due to variation of stability constant of different metal ions. It has been found that the stability constant of zinc and iron are16.1 and 14.4 respectively. Metal with higher stability constant competes with metal of lower stability constant for the chelating agent. As the stability constant of zinc is higher than iron, so zinc can first bind to iron chelator despite of presence of excess iron causing removal of zinc from the body resulting in their deficiency ${ }^{17-18}$.

It has also been suggested that it may be caused due to inverse relationship between zinc and copper. Zinc deficiency is associated with elevated serum copper level as zinc interfere copper absorption and it induce synthesis of intestinal metallothionein. Metallothionein binds with copper causing decreased absorption of copper from intestine and increased fecal excretion. When there is zinc deficiency, metallothionein and ceruloplasmin are also deficient causing increased serum copper level ${ }^{18-21}$

J Bangladesh Soc Physiol. 2019, June; 14(1): 38-42

\section{Conclusion}

From the result of the study, it may be concluded that low serum zinc and high serum copper may occur in TDT patients treated with combined (DFP \&DFO) iron chelator. So, routine estimation of serum zinc and copper levels may be useful to prevent the harmful effect of alteration of these micronutrient concentrations in TDT when patients treated with combined iron chelator.

Conflict of interest None.

Acknowledgement

The authors acknowledge the Department of Hematology and Transfusion Medicine, BSMMU, Dhaka for their kind co-operation during sample collection and Armed Forces Institute of Pathology, Dhaka cantonment regarding laboratory tests.

\section{References}

1. Sultan S, Irfan SM, Kaker J, Zeeshan R. Effect of iron chelator desferrioxamine on serum zinc levels in patients with beta thalassemia major. Malays $\mathrm{J}$ Pathol 2015; 37(1):35-8.

2. Rachmilewitz EA, Giardina PJ. How I treat thalassemia. Blood J 2011;118(13): 3479-88.

3. Galanello R, Origa R. Beta thalassemia. Orphanet J Rare Dis 2010;5(11):1-15.

4. Mahyar A, Ayazi P, Pahlean A, Mojabi H, Sehhat $\mathrm{R}$, Javadi A. Zinc and copper status in children with beta-thalassemia major. Iran J Pediatr 2010;20(3):297-302

5. Amin SK. Prevention of thalassemia by genetic counseling. Anwer khan Mod Med Coll J 2011;2(2):26-8.

6. Tahura S, Selimuzzaman M, Khan W. Thalassemia prevention : Bangladesh perspective - A current update. Bangladesh J Child Health 2016;40(1): 31-8.

7. Baski AJ, Pennell DJ. Randomized controlled trails of iron chelators for the treatment of cardiac siderosis in thalassemia major. Forntiers Pharmacol 2014;5: 217-22

8. Genc GE, Ozturk Z, Gumuslu S, Kupesiz A. Minerals level in thalassemia major patients using different 
iron chelators. Biol Trace Elem Res 2016;170:916.

9. Kannengiesser C, Jouanolle M, Hetet G, Mosser A, Muzeau F, Henry D et al. A new missense mutation in the $\mathrm{L}$ ferritin coding sequence associated with elevated levels of glycosylated ferritin in serum and absence of iron overload. Haematologica 2009;34(3):335-39.

10. Ikram N, Hassan K, Younas M, Amanat S. Ferritin levels in patients of beta thalassemia major. Int $\mathrm{J}$ Pathol 2004;2(2):71-4.

11. Shazia Q, Mohammad ZH, Rahman T, Shekhar U. Correlation of oxidative stress with serum trace element level and antioxidant enzyme status in beta thalassemia major patient: A review of the literature. Anemia 2012;1:1-7.

12. Widad NM, Al-Naama LM, Hassan MK. Trace elements in patients with beta thalassemia major. Haema 2003;6(3):376-83.

13. Erdogan E, Canatan D, Ormeci AR, Vural H, Aylak F. The effect of chelators on zinc levels in patients with thalassemia major. J Trace Elem Med Bio 2013; 27(2):109-11.

14. Mashhadi MA, Sepehri Z, Heidari Z, Shirzaee E, Kiani Z. The prevalence of zinc deficiency in patient with thalassemia in South East of Iran, Sistan and Baluchistan Province. Iran Red Crescent Med J 2014;16(8): e6243.

15. Eithar EK, Salam KM, Nagwa E. An update study of some trace element in patients with thalassemia major.World J Med Sci 2013;9(2):97-101.

16. Mashhadi MA. Copper status in patients with thalassemia major in Zahedan, Iran. Int J Hematol Oncol stem cell Res 2013;7(3):21-4.

17. Sabah N, Al- Thamir, Sherian M, Al-Hussainy. Effect of iron overload and treatment method on serum levels of zinc and copper in beta thalassemia major. Med J Babylon 2011;8(2):263-70.

18. Flora S.J.S, Pachauri V. Chelation in metal intoxication. Int. J. Environ Res Public Health 2010;7(7):2745-88.

19. Bjorklund G. The role of zinc and copper in autism spectrum disorder. Acta Neurobiol Exp 2013;73(2):225-36.

20. Roohani N, Hurrell R, Kelishadi R and Schulin R. Zinc and it's importance for human health. J Res Med Sci 2013;18(2):144-57.

21. Fischer PW, Giroux A and L'Abbe MR. The effect of dietary zinc on intestinal copper absorption. Am J Clin Nutr1981;34(9):1670-75. 